\title{
A Predictive Model for Clinical Asthma Exacerbations Using Albuterol eMDPI (ProAir Digihaler): A Twelve-Week, Open-Label Study
}

Guilherme Safioti ${ }^{1}$, MD; Lena Granovsky ${ }^{2}, \mathrm{PhD}$; Thomas $\mathrm{Li}^{3}, \mathrm{PhD}$; Michael Reich ${ }^{2}, \mathrm{PhD}$; Shahar Cohen ${ }^{4}$, PhD; Yonatan Hadar ${ }^{4}$, MSc; Roy Pleasants ${ }^{5}$, PharmD; Henry Chrystyn ${ }^{6}$, MPharm, PhD; Tanisha Hill ${ }^{3}$, PhD; Michael DePietro $^{3}, \mathrm{MD}$

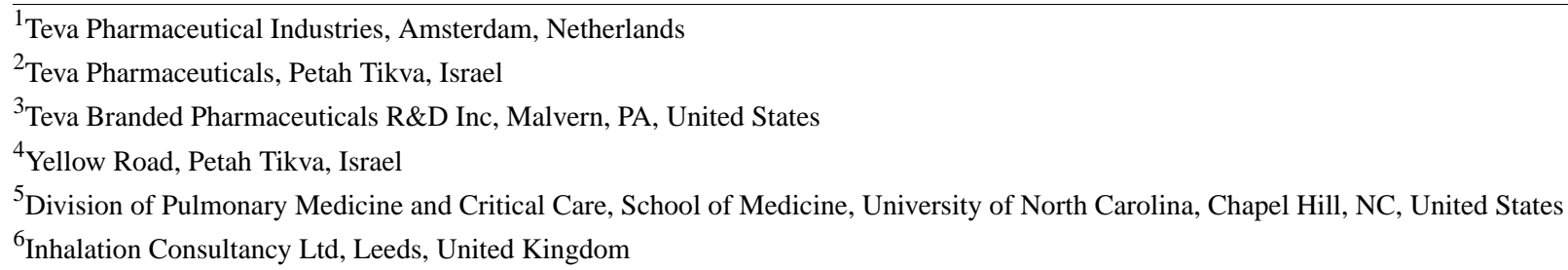

\section{Corresponding Author:}

Guilherme Safioti, MD

Teva Pharmaceutical Industries

107 Piet Heinkade

Amsterdam, 1019 BR

Netherlands

Phone: +310202193000

Email: Guilherme.Safioti@tevapharm.com

\begin{abstract}
Background: The ability to identify an impending clinical asthma exacerbation (CAE) would improve asthma action plans and provide opportunities for pre-emptive treatment. Increased use of inhaled rescue medications, such as albuterol, has been observed in the days prior to a CAE, but other potential predictive factors are poorly understood. Approved by the US Food and Drug Administration (FDA) in late 2018, ProAir Digihaler with built-in sensors registers when patients use the inhaler and has been shown previously to accurately measure both peak inspiratory flow and inhalation volume, confirming the device's ability to reliably record objective information on inhaler usage and technique.
\end{abstract}

Objective: Data collected from the ProAir Digihaler provides, for the first time, a more complete picture of patients' use of inhaled medication, and thereby offers an opportunity to develop a predictive model of an impending CAE, and the potential to better implement asthma action plans and facilitate early treatment.

Methods: Patients ( $\geq 18$ years old) with exacerbation-prone asthma were recruited to a 12-week, open-label study. Patients used the ProAir Digihaler (albuterol $90 \mu \mathrm{g}$ 1-2 inhalations q4 hours) as needed. The electronic component of Digihaler recorded each use and inhalation variables (peak inspiratory flow, volume inhaled, time to peak flow, and inhalation duration). Data were downloaded from the inhalers and, together with clinical data, subjected to a machine-learning algorithm to develop models predictive of an impending CAE as defined by the need for oral corticosteroids. The generated model was evaluated by receiver operating characteristic (ROC) curve analysis.

Results: Three hundred and sixty patients made $\geq 1$ valid inhalation from the Digihaler and were included in the analysis. Of these, 64 patients experienced a total of 78 CAEs. The strongest predictive factor during the 5 days before a CAE was the average number of albuterol inhalations per day. The predictive model was strengthened by supplementing these data with other inhalation features collected by Digihaler, including peak inhalation flow, inhalation volume, night-time usage, and trends of these parameters over time. This model predicted an impending exacerbation over the 5 days with a ROC AUC value of 0.75 .

Conclusions: This study represents, to our knowledge, the first successful attempt to develop a model to predict CAE derived from the use of a rescue medication inhaler device equipped with an integrated sensor and capable of measuring inhalation parameters. The predictive power of the model would benefit from further development with larger populations of asthma patients.

(iproc 2019;5(1):e15173) doi: 10.2196/15173 


\section{KEYWORDS}

asthma; digital; inhaler; predictive; digital inhaler; predictive model; clinical asthma exacerbation; albuterol

Edited by R Palacholla; this is a non-peer-reviewed article. Submitted 25.06.19; accepted 14.08.19; published 02.10.19.

Please cite as:

Safioti G, Granovsky L, Li T, Reich M, Cohen S, Hadar Y, Pleasants R, Chrystyn H, Hill T, DePietro M

A Predictive Model for Clinical Asthma Exacerbations Using Albuterol eMDPI (ProAir Digihaler): A Twelve-Week, Open-Label Study

iproc 2019;5(1):e15173

URL: http://www.iproc.org/2019/1/e15173/

doi: $\underline{10.2196 / 15173}$

PMID:

(C) Guilherme Safioti, Lena Granovsky, Thomas Li, Michael Reich, Shahar Cohen, Yonatan Hadar, Roy Pleasants, Henry Chrystyn, Tanisha Hill, Michael DePietro. Originally published in Iproceedings (http://www.iproc.org), 02.10.2019 This is an open-access article distributed under the terms of the Creative Commons Attribution License (https://creativecommons.org/licenses/by/4.0/), which permits unrestricted use, distribution, and reproduction in any medium, provided the original work, first published in Iproceedings, is properly cited. The complete bibliographic information, a link to the original publication on http://www.iproc.org/, as well as this copyright and license information must be included. 